\title{
Bilateral choroidal metastases from "adenoma" of the bronchus
}

\section{GOLIN WALKER}

\section{Southampton}

Although the literature on so-called bronchial "adenoma" is not inconsiderable, including proved cases of metastasis to the eye in American reports, the condition does not seem to be clearly differentiated in standard works from other lung secondaries to the eye (DukeElder, I 966). A short review of the literature may therefore not be out of place.

That adenomas of the bronchus may be potentially malignant and metastasize appears to be well known to pathologists. Wessler and Rabin (1932) differentiated bronchogenic carcinoma from adenoma and observed that some of these became malignant. Liebow (1952) said that the term "adenoma" was retained through common usage and because when they do invade and metastasize they behave so differently from bronchogenic carcinomas.

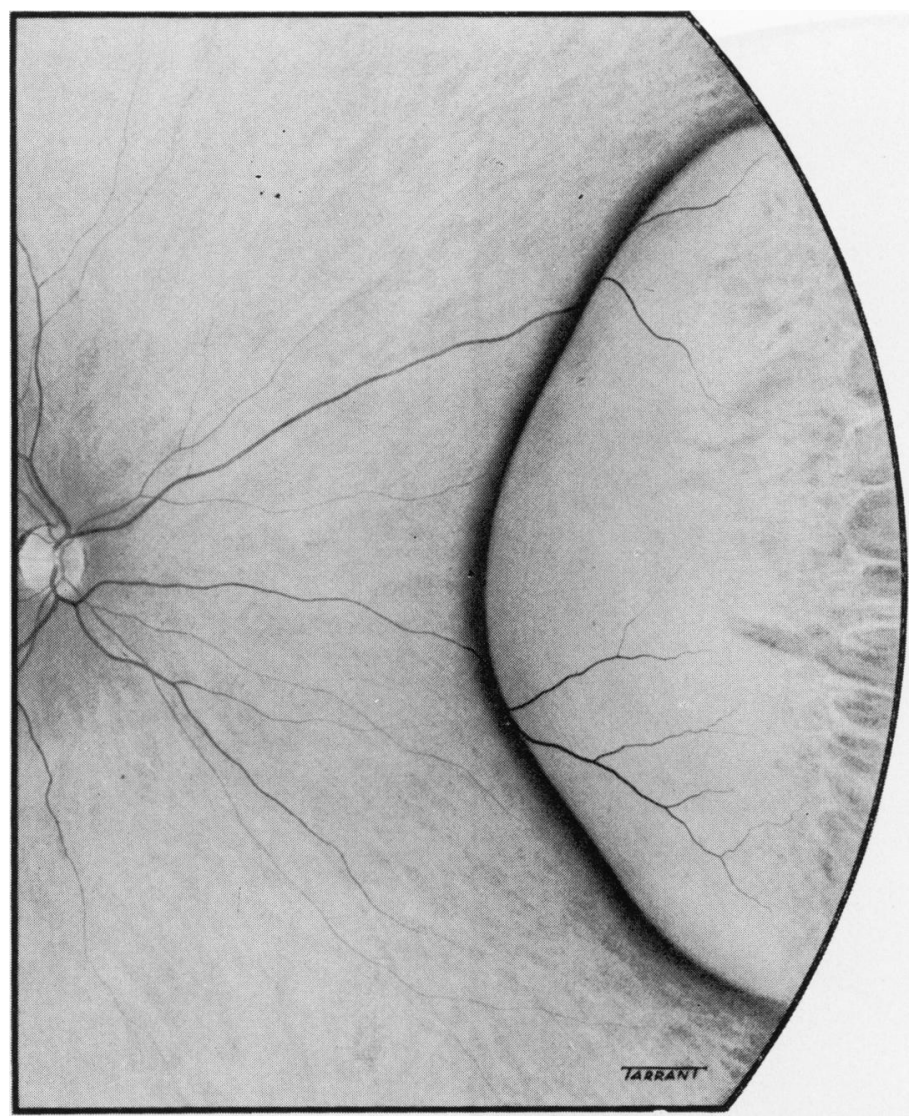

FIG. I Right eye showing large nasal tumour before irradiation

Address for reprints: C. B. Walker, F.R.C.S., Cadenham Close, Cadnam, Southampton SO4 2NS 
Goodner, Berg, and Watson (I96I) described them as "sometimes invasive, sluggishly metastasizing, polypoid or sessile epithelial neoplasms involving the subepithelial tissues usually of the proximal bronchi", and others have also pointed out their non-benign nature: Hudson (1934), Laff and Neubuerger (1944), Goldman (1949), Willis (1952), Hutchison (1952), Ricketts, Price, and Thomas (1955), Rosenbluth, Laval, and Weil (I960), and Tala (1963).

These tumours are related to carcinoid tumours of the intestine but appear to metastasize more commonly (Sandler, Scheuer, and Watt, I96I). Both may produce the carcinoid syndrome associated with 5-hydroxytryptamine in the tumour and large amounts of 5hydroxyindoleacetic acid (5-HIAA), in the urine. Lung tumours are the second commonest source of tumours in the eye and of these $I \cdot 3$ to ro per cent. are derived from bronchial "adenomas" (Font, Kaufer, and Winstanley, 1966).

More recently Turnbull, Huvos, Goodner, and Beattie (1973) reviewed 6i cases of bronchial adenoma, of which 44 were carcinoids. These produced no endocrine syndrome and survival was only 59 per cent. over 5 years.

According to Liebow there is an about equal sex incidence and the average age at treatment is 35 to 40 years. The average duration of pulmonary symptoms is 30 months before diagnosis with an earlier onset in females, chronic cough and haemoptysis being common. Recurrence after incomplete removal may occur in the hilar stump or lymph nodes, but

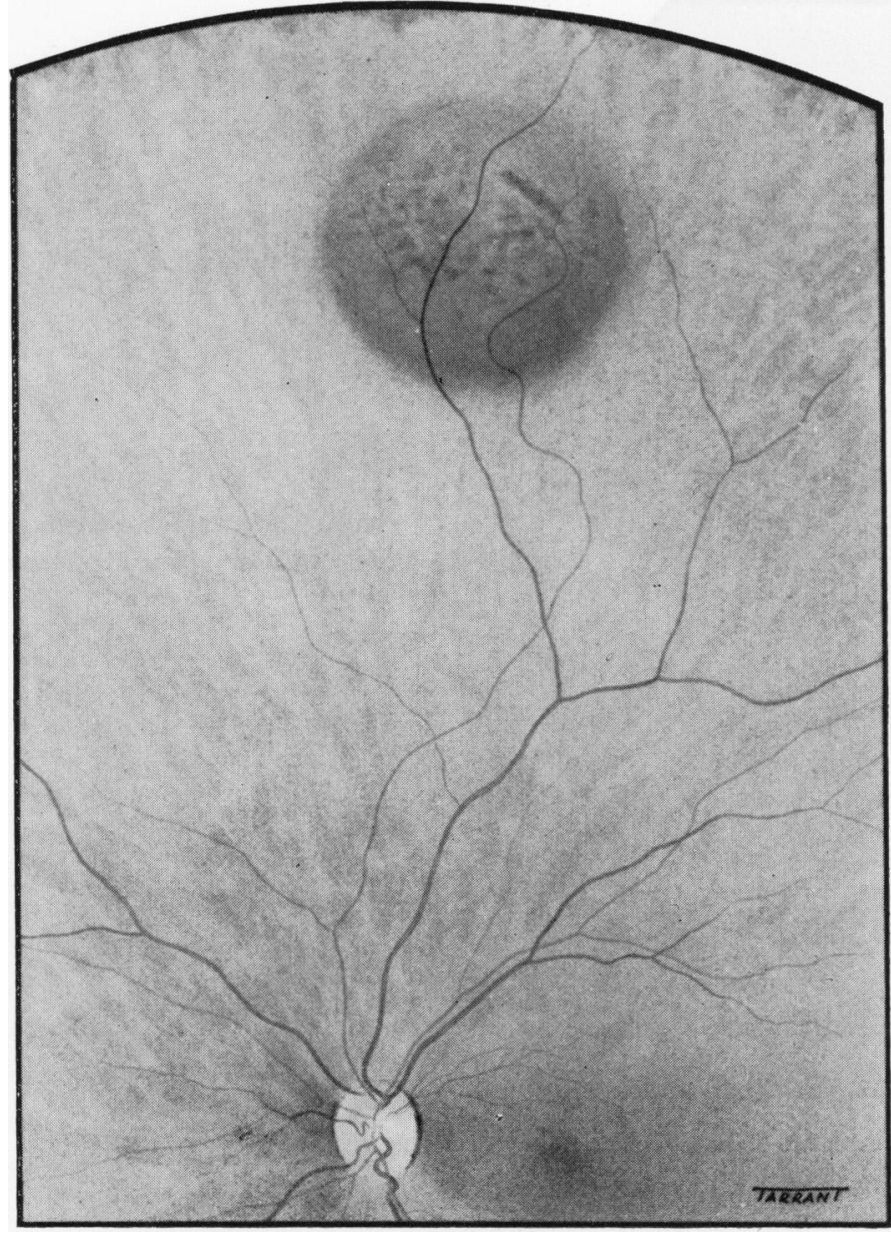

FIG. 2 Left eye showing tumour before irradiation 
many years may elapse. Metastases may occur in the liver, kidney, and other organs. Skin deposits were repeatedly removed in one patient before the eye became involved (Font and others, I966). Goodner and others (I96I) noted an incidence of metastasis of 44 per cent. in 27 patients with bronchial carcinoid. However, these tumours rarely kill by metastases, death being due to bronchiectasis, pneumonitis, haemorrhage, or the complications of surgery.

Reported cases of secondary deposits in the eye all seem to have been choroidal. In the case reported by Ricketts and others (1959), this occurred a few months after the irradiation of a pulmonary mass proved by biopsy. In the case of Rosenbluth and others (1959), a choroidal metastasis occurred 7 years after pneumonectomy. All lesions appeared greyish and non-pigmented, with or without secondary detachment or haemorrhage. They were all posterior to the equator. Only one eye was involved. It was often difficult to make a clinical or even pathological diagnosis from a secondary or unpigmented primary malignant melanoma. Enucleation was performed on the grounds that a primary eye tumour could not be excluded or that the long period of time elapsing since pneumonectomy made a diagnosis of secondary deposit highly improbable. However, in the case of Rosenbluth and others (1960), it seems it was possible to say after 7 years that the eye lesion was histologically compatible with bronchial adenomatous tissue of low-grade malignancy.

The diagnosis of the following case, in which both eyes were involved, rests on the removal by lung resection of a proved bronchial adenoma 4 years previously, a long survival time to date and the satisfactory response of the ocular lesions to local irradiation. Since the more affected eye was not removed it was not possible to obtain pathological confirmation.

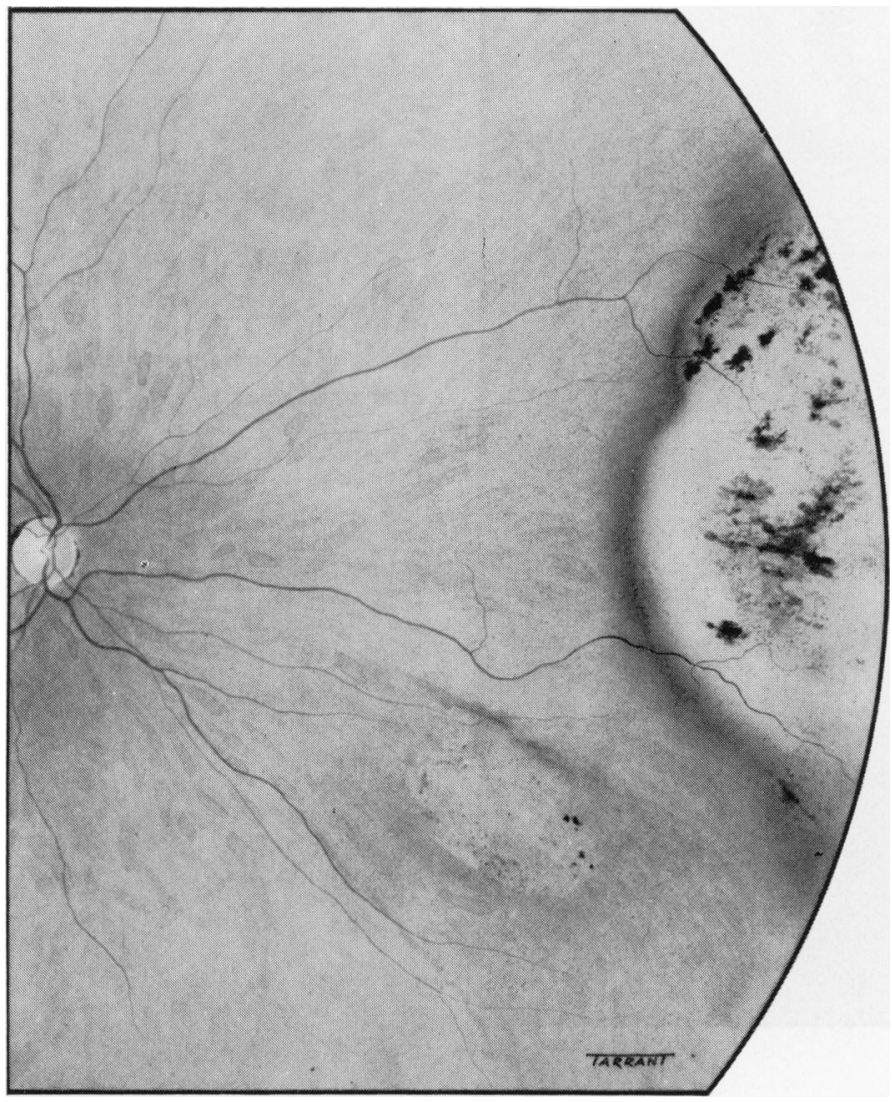

FIG. 3 Right eye showing nasal tumour after irradiation 


\section{Case report}

A married woman aged 38 presented in July, 1964, with blurred vision in both eyes. A low-grade bilateral uveitis was present with macular oedema on the right. A large, non-pigmented, solid detachment protruded from the anterior choroid on the nasal periphery of the right eye with a few small haemorrhages on its surface. There was no serous detachment. In the left eye a small patch, of what was at first thought to be a choroiditis, was present above the equator. Vision was $6 / 60$ right, 6/6 left (Figs $I$ and 2).

A lung resection had been performed 4 years previously for bronchial adenoma which showed no remarkable pathological features, and the patient had been discharged with a good prognosis.

A general medical survey and re-examination of the chest operation did not reveal a primary or recurrence of adenoma. Urinary excretion of 5-HIAA was repeatedly normal. Subsequently the gradual enlargement of both lesions made the diagnosis of secondary deposits from a conjectural source inescapable, although at one stage a primary neoplasm in the right eye was suggested and enucleation was advised.

In December, I964, a $2.50 \mathrm{mC}$ radon seed was secured to the sclera over the lesion in the right eye for Io hours. The medial rectus had to be detached. In February, 1966, a $7.50 \mathrm{~mm}$. Co 60 plaque was applied to the left eye above for a week, and 2 months later the shrinking right lesion was again treated with radon. A most satisfactory result was obtained in that the left lesion disappeared in due

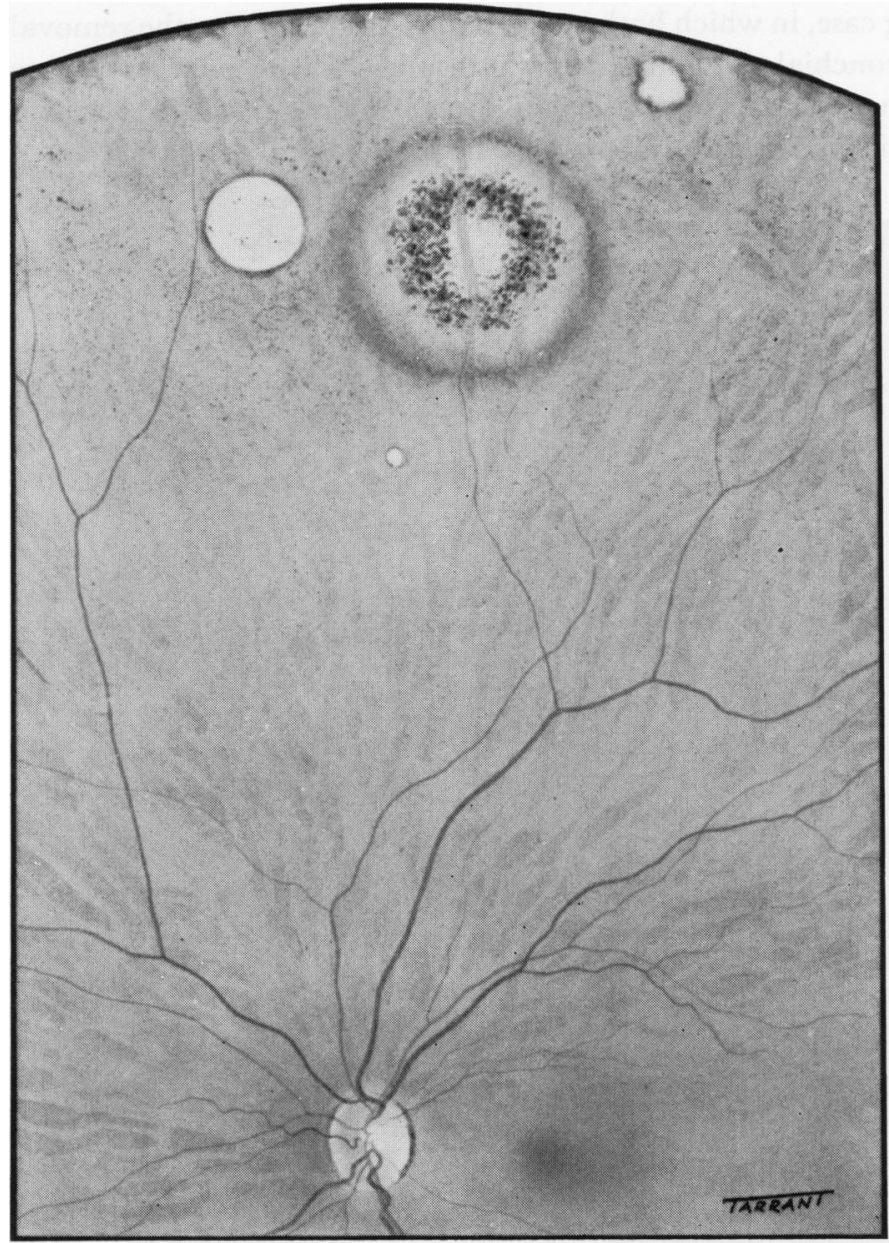

FIG. 4 Left eye showing tumour after irradiation 
course and the right steadily decreased in size, with resolution of the uveitis and macular oedema, until by July, 1967 , wide mydriasis was necessary for its examination (Figs 3 and 4). Vision returned to $6 / 6$ in this eye 3 months after the first application, the second being precautionary in view of the continued presence of a mass, which was nevertheless shrinking.

Examination in July, 1973, established that the patient was still in good health 13 years after the lung resection, and that vision was normal, 6/6 in each eye. At the site of the original tumour in the right eye, no elevation was apparent, a flat irregularly-pigmented scar remaining. The left eye showed choroidal atrophy with exposed sclera.

\section{Summary}

A further case of presumed intraocular secondaries from a bronchial adenoma is described. The slow growth of these tumours and their radiosensitivity is noteworthy. Retention of both eyes to date has not affected the outcome.

Survival for 13 years after pulmonary resection confirms the unpredictable outcome in these cases.

I am grateful to those surgeons who helped me with this difficult case, to Dr. R. A. Goodbody, Director of the Southampton University Area Pathological Service, and the Department of Audio-Visual Communications of the Institute of Ophthalmology.

\section{References}

DUKE-ELDER, s. (1966) "System of Ophthalmology", vol. 9, p. 9 I 7. Kimpton, London FONT, R. L., KaUfer, G., and winstanley, R. A. (1966) Amer. J. Ophthal., 62, 723

GOLDMAN, A. (1949) F. thorac. Surg., I8, I37

GOODNer, J. T., Berg., J. W., and Watson, W. L. (196i) Cancer (Philad.), 14, 539.

hudson, A. c. (1934) Proc. roy. Soc. Med., 27, 304

hUtchison, H. E. (1952) Cancer (Philad.), 5, 884

LAFF, H. I., and NEUBUerger, K. T. (1944) Arch. Otolaryng., 40, 487

LIEBOW, A. A. (1952) "Atlas of Tumor Pathology", Section 5, Fasc. 17, "Tumors of the lower respiratory tract". Armed Forces Institute, Washington D.C.

RicKetTS, M. M., PRICE, т., and thomas, м. (1955) Amer. F. Ophthal., 39, 33

rosenbluth, J., Laval, J., and weil, J. v. (1959) A.M.A. Arch. Ophthal., 63, 47

SANDLER, M., SCHEUER, P. J., and WATT, P. J. (196I) Lancet, 2, 1067

tala, P. (1963) Ann. Chir. Gynaec. Fenn., 52, I

turnbull, A. D., huvos, A. G., goodner, J. T., and Beattie, E. J. (1973) Ann. thorac. Surg., 14, 453 WESSLER, H., and RABIN, C. (1932) Amer. F. med. Sci., 183, I64

willis, R. A. (1952) "The Spread of Tumours in the Human Body", 2nd ed., p. I. Butterworth, London 